\title{
MUJERES EMPRESARIAS. ACCIONES Y ESTRATEGIAS EN ARAGÓN DESDE UNA MIRADA FEMINISTA
}

\author{
María Añover López \\ Dpto de Geografía y Ordenación del Territorio \\ Facultad de Filosofía y Letras. Universidad de Zaragoza \\ mariaanoverlopez@hotmail.com
}

Resumen: Este artículo analiza la realidad de las mujeres emprendedoras aragonesas a través del trabajo de campo utilizando la entrevista semidirigida y observación participante como técnicas de investigación cualitativa feminista para abordar conceptos como infrarrepresentación, trabajo productivo y reproductivo a través de la doble jornada, la segregación horizontal, creación de redes, tiempo, entre otros, en la medida en que una de las consecuencias positivas más relevantes para las mujeres objeto de estudio sería la concienciación de su situación de género a través del análisis de la apertura de su propia empresa como salida ante la discriminación.

Palabras clave: feminismo, emprendedoras, conciliación, segregación horizontal, infrarrepresentación, discriminación.

\begin{abstract}
This article looks at the reality of the Aragonese women entrepreneurs through fieldwork using semistructured interviews and participant observation as feminist qualitative research techniques to address concepts as representation, productive and reproductive work through the double shift, horizontal segregation, networking, weather, among others, to the extent that one of the main positive consequences for women under study is the awareness of the gender situation through the analysis of opening your own business as an output to discrimination.
\end{abstract}

Keywords: feminism, entrepreneurs, conciliation, horizontal segregation, underrepresentation, discrimination. 


\section{Introducción}

Esta investigación parte de la premisa en la que ser una mujer emprendedora significa ser capaz de crear algo nuevo o de dar un uso diferente a algo ya existente y de esa manera generar un impacto en su propia vida y en la de la comunidad en la que habita (Formichella, 2004). Pero, en los últimos tiempos las instituciones políticas y económicas han promovido con ahínco el espíritu empresarial y emprendedor sin hacer diferencias entre ambos conceptos, por lo que en el presente artículo, no hemos hecho diferencias a la hora de nombrar a nuestras protagonistas, ya que ellas mismas no conocían el desacuerdo entre los dos términos y, por lo tanto, se nombraban de ambas formas.

Desde esta mirada, presente trabajo parte de la hipótesis de que el cambio en el rol tradicional de las mujeres occidentales, tanto si se consideran fuerza de trabajo como emprendedoras/empresarias, constituye un activo importante en la dinamización del territorio y en la consecución de la igualdad de géneros a nivel laboral y social. Centrando la atención en las distintas provincias y comarcas, se pretende verificar esta hipótesis, en el marco socioeconómico de Aragón.

Para ello, se abordarán los siguientes objetivos, siguiendo a Mies (1998), que permitirán alcanzar el objetivo general y verificar, en su caso, la hipótesis total o parcialmente:

- La identificación de las dificultades que tienen las mujeres aragonesas: se parte de la idea de que esta situación se manifiesta en la falta de oportunidades y en un sentido del mundo todavía patriarcal que frena la capacidad de acción de las mujeres, tanto en el plano laboral como cultural, político y económico.

- Al señalar que se parte de la idea de que las mujeres están infrarrepresentadas en todos los niveles de la vida social: quiere decirse que son muchas las mujeres que viven en una situación a medio camino entre el papel tradicional de soporte de familia y el de emprendedora. Esas mujeres trabajan a jornada completa, pero su trabajo, la mayoría de las veces, no es reconocido socialmente ni aparece en las estadísticas oficiales, por lo que se puede hablar de un trabajo invisible.

- Pretendo tener en cuenta la discriminación directa e indirecta: entendiendo por tal lo que define Gamonal Contreras (2003), que coincide con la perspectiva de investigación que se sigue en este trabajo. Para el autor citado, la discriminación es una situación en la que una persona o grupo es tratada de forma desfavorable a causa de prejuicios, generalmente por pertenecer a una categoría social distinta. Entre estas categorías se encuentra la raza, el género, la religión, el rango socioeconómico, la edad y la discapacidad. La que nos interesa en este trabajo es la referente al género y su relación con el mercado laboral. En este punto, interesa aclarar que hablamos de discriminación directa cuando nos referimos a la desigualdad de oportunidades entre hombres y mujeres, característica persistente 
en la vida social, económica y política, a pesar de algunos cambios positivos para las mismas. Al hablar de "discriminación indirecta" me refiero, sobre todo, a las diferentes estrategias de desarrollo que se suelen centrar en los grupos de gran volumen, como por ejemplo, el conjunto de mujeres emprendedoras. Sumado a estas cuestiones, considero que existe un desconocimiento de las medidas o estrategias para la igualdad imperantes (acciones positivas y Mainstreaning) por parte de los agentes sociales, políticos y técnicos, como consecuencia de una ausencia de formación e información en teorías y prácticas feministas.

- La identificación de la falta de población femenina con edades comprendidas entre 18-40 años: interesa en particular porque la ciudad suele identificarse con lugares donde existe una mayor independencia para las mujeres que rebasa aspectos económicos, ya que la realización personal es la clave de estas decisiones, es decir, de dejar sus núcleos rurales de origen. Si a esto le sumamos que otra de las transformaciones que más ha contribuido al cambio en la vida de las mujeres ha sido su inclusión definitiva en el sistema educativo, el resultado es que las limitaciones que para muchas jóvenes tiene la vida en los pueblos, tanto en el plano familiar como en la actividad y relaciones externas a la familia, hace que muchas hayan optado por aprovechar una mayor formación en la búsqueda de empleos urbanos, que les permitan tener una vida independiente y tomar decisiones al margen del grupo de origen.

- El intento de valorar los aspectos de las mujeres empresarias, tanto los positivos como los negativos, permitirá, por un lado, investigar si emprendiendo sus propios negocios han alcanzado mayores niveles de justicia y de igualdad, tanto en el aspecto económico y social, como en el cultural o educativo. Por otro, me proporcionará la ocasión de analizar en qué grado son las propias mujeres las principales reforzadoras de sus actividades tradicionales, aun mostrándose transgresoras en otros aspectos, y si esta situación puede ser debida a factores como el hábito y la costumbre en la educación o la ausencia, al menos hasta ahora, de propuestas concretas a su favor y de nuevos modelos de cambio.

- Con la clasificación de las actividades a las que se dedican las mujeres emprendedoras: se pretende verificar que las mujeres aragonesas forman un grupo heterogéneo y constatar cuántas se dedican a la realización de tareas tradicionales asociadas, derivadas de su inscripción genérica (tanto dentro del hogar como fuera de éste) y extraer, asimismo, la experiencia de aquellas otras que siembran el futuro para las nuevas generaciones, con otro tipo de actividades no directamente relacionadas con unos roles específicamente "femeninos": elevando los niveles de educación, transformando los lugares de trabajo, incrementando su participación en la actividad empresarial, formando asociaciones, etc.

- Con la pregunta dedicada al tiempo libre: el tiempo es una magnitud física pero también una magnitud humana, subjetiva por ende, y medible en función de nues- 
tra experiencia vital. El tiempo de las mujeres ha sido el tiempo dedicado a los demás, al cuidado, a la reproducción, al mantenimiento de los lazos familiares, a la dedicación "en cuerpo y alma" a la construcción de la familia, "base de la sociedad". Así, las mujeres han ido quedando relegadas de sí mismas, en un largo camino de postergación de lo propio, fueran intereses, deseos, proyectos, ideas. Desde hace más de un siglo el feminismo lucha por devolver el tiempo robado a las mujeres. Su tiempo privado, su tiempo de ocio, su tiempo de desarrollo intelectual, su tiempo público, su tiempo social y su tiempo de participación ciudadana.

- Por último, mediante la identificación y valoración de las redes y de las características de las actividades laborales que desarrollan: se pretende constatar en qué medida las mujeres emprendedoras han protagonizado la transformación de la situación socioeconómica de la provincia, en el sentido en que en ellas ha residido la responsabilidad de negociar con las administraciones e ir rompiendo ciertos roles y limitaciones de carácter tradicional, para convertirse en una nueva voz. Ahora, las mujeres debaten, participan en actos públicos como el del Día Internacional de la Mujer o los Encuentros de Mujeres Emprendedoras en las diferentes comarcas, asumen responsabilidades dentro y fuera del hogar, y, si todo va bien, gracias a la concienciación colectiva jugarán un papel decisivo a la hora de transformar los roles relacionados con ellas en el futuro de las provincias aragonesas.

Así, la finalidad del presente artículo es la de conocer las diferentes realidades existentes marcadas por el término "género", que han dado lugar a que las pautas de vida en el medio estudiado hayan tenido un carácter patriarcal a lo largo de la historia, hasta que las mujeres adquirieron el protagonismo que se merecían mediante la apertura de sus propios negocios.

\section{Marco teórico}

La perspectiva de género en las ciencias sociales, sobre todo en antropología y geografía, ha evolucionado desde un enfoque de "añádanse mujeres y agítese" a estudios diversos que se apoyan en la teoría feminista plasmada en una fértil literatura internacional (Swain, 2005: 27). De este modo, la definición de género para el caso que nos ocupa es la siguiente:

Género, por tanto, se utiliza aquí para referirnos a un sistema de identidades culturalmente construidas, expresadas en ideologías de masculinidad y feminidad, que interactúan con relaciones socialmente estructuradas mediante las divisiones del trabajo y el placer, la sexualidad y el poder y entre los hombres y las mujeres (Swain, 1995: 258-259). 
A partir de la presente definición, nos centraremos en la división del trabajo entre los hombres y mujeres. Precisamente, desde una postura crítica, la literatura feminista se replantea la existencia de una lógica capitalista general e indaga en la particular manera en que se construyen las relaciones de las mujeres con el mercado de trabajo, con el capital, con los cargos, con las calificaciones y con los salarios. Algunas autoras se han centrando en el análisis del proceso de trabajo y en su división horizontal y vertical en la empresa, mostrando la segregación de las mujeres en la estructura del empleos. Así, Braverman (1974) por ejemplo, explica la feminización de puestos de trabajo en la industria, centrándose en los mecanismos de calificación-descalificación de la fuerza de trabajo que se producen en las reestructuraciones de los procesos de producción capitalista. Es decir, observa que al producirse la descalificación de determinadas tareas en el sector servicios, éstas son ocupadas por mano de obra femenina. Sin embargo, no logra explicar porqué son las mujeres las que se incorporan para realizar esos trabajos. Con nuevos aportes de las feministas socialistas y en el marco de los análisis de clase-género, la división sexual del trabajo es entendida como un hecho asociado a las jerarquías de género. Autoras como Beechey (1999) y Souza (1986) entre otras, vuelcan su atención en la división sexual de las tareas a nivel del proceso de trabajo. Y allí se hace evidente que hay ciertas cualidades que son atribuidas como propias de la fuerza de trabajo femenina o de la fuerza de trabajo masculina y que, por consiguiente, van a definir los trabajos como femeninos o masculinos influyendo esto en la elección de las mujeres a la hora de emprender.

Si ahora nos centramos en el empresariado, tal como nos muestra el artículo de Pérez-Quintana y Hormiga (2013) dedicado a los estereotipos de género y la intención de emprender, sobre este tema, la literatura clásica sobre emprendimiento femenino ha analizado básicamente la brecha de género desde el punto de vista del sexo, limitándose a medir y describir las diferencias entre los empresarios y empresarias (Rob y Matson, 2008; Watson y Robinson, 2003; Kwonget et al., 2012), así como las diferencias entre los tipos de negocios que crean y sus indicadores basados en principios de racionalidad económica (Manolova et al., 2012; Marlow y Mcdow, 2013; Verveul et al., 2005). En cambio, existen otros trabajos que proponen la superación de planteamientos biologicistas y esencialistas partiendo de la construcción social del género o de teorías feministas y aportando interpretaciones que giran en torno a la persistencia de estereotipos de género y a la influencia que ello ejerce en la intención de emprender de hombres y mujeres puesto que el arquetipo de empresario se sitúa en la esfera de lo masculino (William y Best, 1982; Wood y Eagly, 2002; Gupta y Bhane, 2007).

Partiendo de estos planteamientos, la situación será difícil para la mayoría de las mujeres que pretendan optar por la apertura de sus empresas en trabajos masculinizados o que tengan que conciliar su vida laboral y familiar. De esta manera, los rasgos comunes de las mujeres empresarias o emprendedoras se pueden sintetizar en tres hechos: en primer lugar, las tareas reproductivas siguen recayendo en ellas, de ahí que el mundo empresarial se situé en el universo masculino; En segundo lugar, desde el punto 
de vista económico, destaca la importancia de su participación en actividades múltiples, muchas de ellas como capital social; En tercer lugar, los procesos de cambio recientes de Aragón han puesto de manifiesto la elevada participación de las mujeres en la diversificación económica, ocupando el papel de protagonistas en muchos de los nuevos sectores desarrollados a lo largo de los años 90, siendo uno de los mejores ejemplos la apertura de empresas en el sector servicios, tal y como veremos a través de la muestra seleccionada de mujeres empresarias.

Sumado a estas cuestiones, la bibliografía existente en relación con el tema de este trabajo me ha permitido contrastar mi análisis con los resultados de otras investigaciones y comparar las características y situación de las emprendedoras en otros contextos, tanto a nivel estatal, como autonómico, además de en Aragón y algunas de sus comarcas. En este sentido, los diferentes estudios sobre el empresariado femenino en España como los realizados por Romero $(1990,1994,2005)$, han sido útiles para tener una noción clara sobre los retos culturales a los que se han tenido que enfrentar las empresarias de nuestro país para conseguir el reconocimiento que se merecen. Sumado a esto, el estudio realizado posteriormente por Camarero (2008), me ha servido como ejemplo, en cuanto a la descripción de la noción de trayectoria de las mujeres emprendedoras rurales a nivel estatal, entendida esta, como el proceso vital de las mujeres entre el trabajo productivo y reproductivo. Desde esta mirada, el trabajo masculino no está condicionado por estas causas, así este último, se presenta lineal en su trayectoria en comparación con el femenino, aspecto constatado en la muestra estudiada en el presente artículo.

A nivel autonómico, los estudios enmarcados en Castilla Leon realizados por Rico y Gomez García (2003, 2005), Maya e Hidalgo (2006), en Cataluña llevados a cabo por García Ramón (1989, 1999, 2000, 2005) y en Andalucía los realizados por Ortiz (2007) centrados en el mundo rural, me han servido para poder identificar el tipo de actividades empresariales que realizan las mujeres, así como su perfil personal. En estos, se intenta poner de manifiesto en qué medida las actividades que desempeñan las mujeres empresarias rurales son cada vez más importantes para lograr la recuperación económica y social de muchos pequeños pueblos. De esta forma, su contribución en el desarrollo de las áreas rurales se considera un aspecto de especial reconocimiento en el marco general de las estrategias de desarrollo rural. Por último, me gustaría señalar el estudio realizado a nivel provincial por Nieto (2004) en Málaga dedicado a las empresarias rurales, en el que se señala la apertura de su propio negocio como respuesta a la discriminación al mercado laboral.

Finalmente, en el caso de Aragón existen escasos estudios dedicados a la mujer empresaria. En este sentido, tan solo podemos citar el realizado en el marco de la Cátedra de la Mujer sobre el Empresariado femenino en Aragón, llevado a cabo por Bruscas (2009). Esta investigación ofrece información sobre la antigüedad, tamaño de las empresas, actividades desarrolladas, forma jurídica, características tecnológicas, recursos humanos, beneficios generados o fuentes financieras utilizadas, pero todo ello desde 
una perspectiva exclusivamente económica, dejando a un lado la perspectiva feminista. También se han consultado estudios desde un ámbito complementario de geografía regional de género sobre diferentes comarcas pertenecientes a la comunidad autónoma de Aragón, como el de Castelló, Frutos y Hernández (2009).

No obstante, cabe señalar que el presente estudio, a diferencia de los anteriormente citados, en cuanto investigación social se refiere se plantea un enfoque alejado de las perspectivas economicistas y biologicistas, centrándonos en planteamientos teóricos y metodológicos feministas sobre el mercado laboral y su relación con las jerarquías de género y con los estereotipos sobre la masculinidad y feminidad, todo ello desde una perspectiva geográfica y antropológica e incorporando técnicas de análisis cuantitativas y cualitativas que permitan deconstruir las categorías convencionales de los sistema de género vigentes en el emprendimiento femenino en Aragón.

\section{Fuentes y metodología}

\subsection{Fuentes estadísticas}

Este estudio se ha servido de datos estadísticos facilitados el Instituto Aragonés de Estadística (IAEST): bases territoriales (municipio, entidades...), cartografía, demografía (pirámides de población, tasas de natalidad, entre otros...), estadística local, estadísticas laborales (tipo de jornada, contratos, profesiones...), todos ellos desglosados por sexo y edad en la mayoría de los casos. También hay que resaltar que no hemos tenido la oportunidad de estudiar a mujeres inmigrantes empresarias pues no aparecían en las fuentes disponibles.

Sumado a esto, hay que destacar que los datos facilitados para completar la muestra, han sido cedidos por la Asociación de Mujeres Empresarias de Aragón (ARAME), Asociación de Mujeres Empresarias de Huesca (AMEPHU), y por la Cámara de Comercio y su programa PAEM, dedicado al apoyo empresarial de mujeres, a través de estadísticas realizadas por las mismas entidades a sus asociadas en los dos primeros casos, y a sus usuarias, en el último. De este modo, observamos las 83 empresas asociadas en ARAME (Asociación de Mujeres Empresarias en Aragón) y las 119 en AMEPHU (Asociación de Mujeres Empresarias de Huesca) también decidimos constatar más datos a través del PAEM, siendo 56 las empresas creadas por mujeres en el 2010 y 2011. Así, a través de estas clasificaciones ha sido posible, en primer lugar, determinar el grado de dispersión de las profesiones, viendo como el sector terciario está claramente feminizado, además de constatar la heterogeneidad en la selección de actividades en las que deciden abrir su empresa. Además se han realizado algunas preguntas a las técnica del PAEM y a las presidentes de las asociaciones estudiadas con el objetivo de conocer el perfil de mujer empresaria, no hemos aportado los ítems ya que fueron en- 
trevistas informales compuestas por preguntas referentes sobre el tipo de actividad que desempeñan, edad de las mujeres empresarias y la formación de las mismas, y el por qué deciden abrir su propia empresa.

\subsection{Metodología cualitativa}

Con el fin de aplicar una metodología cualitativa feminista Mies (1998: 26-27) establece unas líneas-guía para llevarla a cabo:

- El postulado de una investigación libre de valores, de neutralidad e indiferencia hacia los "objetos" de investigación, debe ser reemplazado por una parcialidad consciente, que se logra por medio de una identificación parcial con los objetos de la investigación.

- La relación vertical entre el investigador y los "objetos de investigación", la "visión desde arriba", ha de ser reemplazada por la "visión desde abajo". Ésta es una consecuencia necesaria de la parcialidad consciente y de la reciprocidad. La investigación debe ser realizada para servir a los intereses de los grupos dominados, explotados y oprimidos, particularmente a la mujer, cuando lo es.

- El "conocimiento de espectador", contemplativo y no involucrado, ha de ser reemplazo por una participación activa en las acciones, movimientos y luchas feministas. En este sentido, los sujetos investigadores feministas tendremos que involucrarnos en asociaciones y colectivos feministas para no reducir los estudios sobre la mujer a una mera investigación académica descriptiva y poder llegar así a un cambio social.

- El proceso de investigación debe convertirse en un proceso de "concienciación feminista" tanto para los científicos sociales que realizan la investigación como para los sujetos investigados.

A partir de los planteamientos de Mies (1998) desarrollamos las técnicas cualitativas a través del trabajo de campo, centrándonos en la entrevista semidirigida y la observación participante, que contribuyen a disponer de una información complementaria a la que nos ofrecen los indicadores cuantitativos utilizados y más centrada en aspectos relativos a la percepción de la realidad y la experiencia, en términos de vida de los sujetos de la comunidad cotidiana, en este caso, las mujeres emprendedoras en Aragón. Todo ello, relacionado con la identidad de género en la diversidad de las experiencias de las mujeres en el mercado laboral y con las relaciones entre la construcción de la feminidad y la masculinidad y el empleo a través de una mirada crítica feminista.

En total, se han realizado 61 entrevista, hemos seleccionado a las entrevistadas a través de las asociaciones de empresarias y del programan de la cámara de comercio men- 
cionado anteriormente, así que pudimos contar con mujeres de diferentes edades, de diferentes niveles de instrucción y ocupaciones, de diferentes lugares, pero con una característica común, la apertura de su propio negocio en el medio geográfico estudiado. Las entrevistas han sido realizadas vía internet e in situ. Así, con la primera técnica recopilamos 25 cuestionarios, mientras que las entrevistas semidirigidas fueron 36, primando a las emprendedoras de las diferentes comarcas frente a las pertenecientes a las capitales provinciales, debido a que en las zonas rurales los sistemas de género patriarcales se mantienen más latentes. Asimismo, se ha tomado como ejemplo a mujeres que no son destacables de la vida social y política, pero que constituyen un referente como emprendedoras, es decir, representan los nuevos modelos emergentes en los sistemas de género, en el sentido de aquello que merece la pena ser imitado (Del valle, 2002: 11).

La encuesta vía internet, con los mismos ítems que la entrevista semidirigida realizada in situ, nos ha parecido útil en este estudio, pues está especialmente ligada a la siguiente cuestión:

- Cuando no se puede utilizar la técnica de observación directa por factores económicos o contextuales. En este caso, es debido a factores contextuales, como es el poco tiempo del que disponen las mujeres entrevistadas al tener que conciliar su vida laboral y familiar. Aquí, cumplimos la metodología de Mies (1998), cabe resaltar el principio de "visión desde abajo" ya que nuestra investigación feminista debe de servir para terminar con la opresión de género, y que mejor forma que conocer las situaciones de un universo más amplio para poder llegar a un cambio social en el sistema patriarcal, concienciando a estas mujeres de su situación desde una perspectiva crítica de género.

Por estos motivos, utilizaremos tanto testimonios que provienen del cuestionario vía internet como de la entrevista semidirigida, no haciendo diferenciación alguna entre ambos. Las 36 entrevistas realizadas mediante el trabajo de campo in situ fueron llevadas a cabo mediante grabadora para tener una mejor apreciación a la hora de la transcripción de las mismas. El resto, es decir, los 25 cuestionarios vía internet, se realizaron mediante correo electrónico, aquí insistir que para aclarar algunas cuestiones, tuvimos que volver a llamar por teléfono a este último grupo de entrevistadas, la mayoría pertenecientes a las capitales provinciales. De esta forma, obtuvimos una mejor percepción de sus respuestas, sobre todo, las relacionadas con los aspectos más vivenciales, es decir, con sus trayectorias entre el trabajo productivo y reproductivo a la hora de abrir su empresa.

Las entrevistas a las mujeres empresarias se han llevado a cabo en diferentes poblaciones: en núcleos semiurbanos como Barbastro, Sariñena, Jaca, Sabiñanigo, Utebo, Ejea de los Caballeros y Calatayud, y en núcleos rurales más pequeños, como Adahuesca, Lanuza, Estadilla, Alumnias de Rodellar Calamocha o Albarracín, entre otros, así como en las diferentes capitales de provincia, todo ello para constatar cómo la vi- 
sión del mundo rural y urbano se dualiza (Tablas 1). También se ha primado Huesca, porque es la provincia con más empresas femeninas dentro de nuestra Comunidad Autónoma, tal y como pudimos comprobar a través de los datos aportados por las expertas de las diferentes entidades entrevistadas. Todo ello permitió encontrar una mayor diversidad de mujeres emprendedoras y de respuestas. Para preservar el derecho a la intimidad no aparece ningún nombre ni ninguna otra variable que las pueda identificar, respetando el principio de confidealidad en la investigación social, en general, y, en la feminista, en particular. En la tabla que presentamos a continuación, realizamos una distinción entre las técnicas utilizadas a la hora de entrevistar a las mujeres para tener una mejor visión de la metodología cualitativa utilizada.

Tabla 1. Número de entrevistas realizadas por municipios y provincias

\begin{tabular}{|c|c|c|c|c|}
\hline Provincias & Municipios & In situ & Internet & $N^{o}$ entrevistas \\
\hline \multirow[t]{9}{*}{ Huesca } & Huesca & 6 & 8 & 14 \\
\hline & Adahuesca & 1 & $*$ & 1 \\
\hline & Lanuza & 2 & $*$ & 2 \\
\hline & Almunia de Rodellar & 1 & $*$ & 1 \\
\hline & Estadilla & 1 & $*$ & 1 \\
\hline & Jaca & 2 & 1 & 3 \\
\hline & Sariñena & 4 & 2 & 6 \\
\hline & Sabiñanigo & 1 & $*$ & 1 \\
\hline & Barbastro & 4 & 3 & 7 \\
\hline \multirow[t]{4}{*}{ Teruel } & Teruel & 1 & 1 & 2 \\
\hline & Calamocha & 2 & 1 & 3 \\
\hline & Albarracín & 1 & $*$ & 1 \\
\hline & Sarrión & 1 & $*$ & 1 \\
\hline \multirow[t]{5}{*}{ Zaragoza } & Zaragoza & 3 & 7 & 10 \\
\hline & Utebo & 1 & $*$ & 1 \\
\hline & Cariñena & 2 & $*$ & 2 \\
\hline & Ejea de los Caballeros & 2 & 1 & 3 \\
\hline & Calatayud & 1 & 1 & 2 \\
\hline & Total & 36 & 25 & 61 \\
\hline
\end{tabular}

Fuente: Entrevistas realizadas, elaboración propia 
Las variables a tener en cuenta a la hora de seleccionar a las entrevistadas han sido la edad, el tiempo que llevan viviendo en el municipio, el nivel de instrucción y el sector de actividad al que se dedican. La distribución porcentual de las variables respecto al total de la muestra está representada en los Gráficos 1, 2, 3.

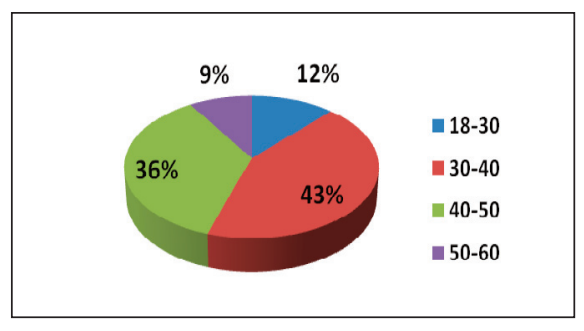

Gráfico 1. Intervalos de edad.

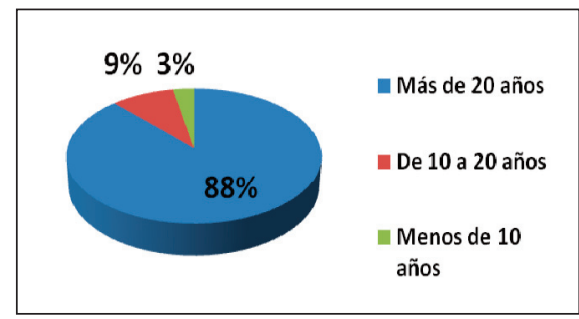

Gráfico 2. Tiempo en el municipio.

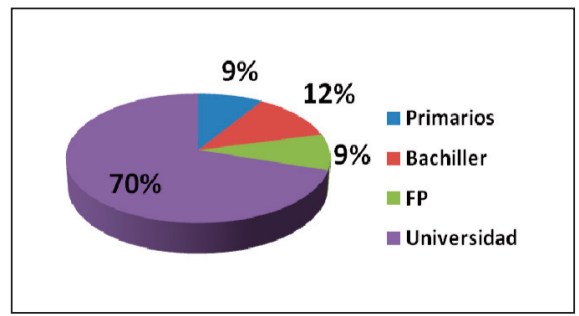

Gráfico 3. Nivel de Instrucción.

Fuente: Entrevistas y encuestas realizadas, elaboración propia.

El perfil predominante de emprendedora entrevistada y encuestada es el de una mujer de 30 a 40 años (43\%), cuyo núcleo de origen es el municipio en el que ha abierto su empresa (88\%), como podemos observar en el gráficos 1 y 3. En cuanto al nivel de instrucción, la mayoría de las mujeres entrevistadas o encuestadas cuentan con estudios universitarios (70\%), ya sea diplomatura o lincenciatura (Gráfico 2) y su negocio está orientado al sector servicios, en la rama de "servicios a la población". Suelen tener hijos a su cargo. No obstante, también se entrevistó a mujeres en el intervalo de edad de 40 a 50 años (36\%), que presentan las mismas características; este último perfil coincide con el tipo de usuarias que se acercan al PAEM a solicitar información de las posibilidades de montar un negocio, tal y como pudimos comprobar a través de la entrevista semidirigida a la técnica encargada de la dirección del programa. Igualmente se han entrevistado a mujeres de más de 50 años (12\%), ya que este grupo aportaba otros puntos de vista, puesto que estas han sufrido más trabas en el acceso a la educación y recursos. 
En este sentido, se pueden identificar dos categorías principales de mujeres empresarias en Aragón tal y como pudimos comprobar a través de las entrevistas realizadas y que también nos constaron las personas encargadas de gestionar las asociaciones de empresarias analizadas:

- Aquellas que han decidido ser su propia jefa: muchas de estas mujeres, tienen una buena formación y en sus trabajos anteriores habían llegado a puestos de gerencia media o superior. También, algunas se estancaron mientras sus compañeros masculinos seguían escalando (techo de cristal) y otras perdieron sus empleos a consecuencias de reestructuraciones o reducciones de plantillas.

- Aquellas para las que la creación de una empresa o el autoempleo es la única posibilidad de obtener ingresos: fueron requisitos indispensables a la hora de emprender en femenino, en primer lugar, la falta de formación específica, sobre todo en los grupos de edad que comprenden de los 50 a 60 años. Estas mujeres han decidido abrir su propio negocio cuando sus hijos/as han salido a estudiar fuera, es decir, una vez que las exigencias y prioridades familiares ceden espacio para otras actividades. Un gran número se dedica a la agroindustria o al sector servicios. Además, pueden decidir en la mayoría de los casos sus propios horarios.

\section{Emprender en femenino en Aragón}

Las dificultades por las que pasa la economía española en su conjunto condicionan el comportamiento de la economía aragonesa que, además, comparte con su entorno una serie de rasgos que justifican la coyuntura que actualmente está atravesando.

La estructura poblacional de Aragón y España pone de manifiesto que el número de mujeres es ligeramente superior al de hombres, aunque en el ámbito rural estos términos se invierten. La tasa de feminidad es un indicador evidente de ese desequilibrio ya que expresa la cantidad de mujeres por cada 100 hombres, que si para Aragón es de 100,6\%, en el 2012, en la escala comarcal sólo superan la media regional las que incluyen la capital provincial y entre las comarcas, la de Somontano de Barbastro.

Si ahora atendemos a la división por sexos de las personas afiliadas al régimen especial de autónomos a nivel autonómico, vemos como, en el especial agrario, el 23,48\% de las afiliadas son mujeres; en el sector de la construcción tan sólo 8,96\%; en el industrial, 27,44\%, mientras que en el sector servicios el porcentaje asciende a un 42,10\% respecto al total de población afiliada.

A partir de estos datos, si descendemos al ámbito provincial (Tabla 2), vemos que tanto a nivel autonómico como provincial, los servicios son la actividad que eligen más del 40\% de las emprendedoras superando el 45\% en Zaragoza; en la industria, las cifras 
oscilan entre el 25\% y 30\% mientras la construcción aglutina menos del 10\% de las mujeres; en lo que se refiere al sector agrícola, en Zaragoza y Huesca ocupa a un 21\% de la población femenina autónoma, mientras que en Teruel a un 31\% y es en esta actividad donde hay una diferencia significativa entre esta provincia y el resto del territorio.

Tabla 2. Sectores de producción, Régimen Especial de Autónomos por sexos, Provincias, 2009

\begin{tabular}{|l|l|r|r|r|c|c|}
\hline Territorio & Sector actividad & Hombres & Mujeres & Total & Hombres \% & Mujeres \% \\
\hline Aragón & Agricultura & 15.727 & 4.826 & 20.553 & 76,52 & 23,48 \\
Aragón & Construcción & 14.865 & 1.464 & 16.329 & 91,03 & 8,97 \\
Aragón & Industria & 6.730 & 2.546 & 9.276 & 72,55 & 27,45 \\
Aragón & Servicios & 36.181 & 26.315 & 62.496 & 57,89 & 42,11 \\
\hline Huesca & Agricultura & 5.887 & 1.506 & 7.393 & 79,63 & 20,37 \\
Huesca & Construcción & 3.309 & 283 & 3.592 & 92,12 & 7,88 \\
Huesca & Industria & 1.130 & 469 & 1.599 & 70,67 & 29,33 \\
Huesca & Servicios & 6.246 & 5.043 & 11.289 & 55,33 & 44,67 \\
\hline Teruel & Agricultura & 3.384 & 1.588 & 4.972 & 68,06 & 31,94 \\
Teruel & Construcción & 2.297 & 168 & 2.465 & 93,18 & 6,82 \\
Teruel & Industria & 773 & 258 & 1.031 & 74,98 & 25,02 \\
Teruel & Servicios & 3.284 & 2.790 & 6.074 & 54,07 & 45,93 \\
\hline Zaragoza & Agricultura & 6.456 & 1.732 & 8.188 & 78,85 & 21,15 \\
Zaragoza & Construcción & 9.259 & 1.013 & 10.272 & 90,14 & 9,86 \\
Zaragoza & Industria & 4.827 & 1.819 & 6.646 & 72,63 & 27,37 \\
Zaragoza & Servicios & 26.651 & 18.482 & 45.133 & 59,05 & 40,95 \\
\hline
\end{tabular}

Fuente: laest, elaboración propia, Unidad: número de personas y porcentaje.

Así, el sector de los servicios está considerado como el sector "femenino" por naturaleza, de ahí también que una proporción importantísima de empresas dirigidas por mujeres se establezcan en el sector. La opción empresarial, por lo tanto, también se caracteriza por un sesgo de género. De esta manera, el empleo de las mujeres se caracteriza por una alta concentración en pocas actividades, ramas y categorías y debe reconocerse como una clara manifestación de la segmentación horizontal del empleo. También hay que considerar que las mujeres pueden insertarse de manera masiva a este sector como una respuesta a la construcción social de trabajo femenino, dado que las identidades construidas en el ambiente familiar se proyectan y refuerzan en la división sexual del trabajo, por ejemplo, actualmente juegan un rol determinante en el bienestar y desarrollo social la educación y la salud. 


\subsection{Identificación de las dificultades}

La identificación de las dificultades de las mujeres se inscribe sobre todo en las barreras proclamadas como señas de identidad social en el mundo rural, entre otras son el apego a la tradición, los fuertes vínculos familiares y el mantenimiento de relaciones sociales cercanas; todo ello unido al mantenimiento de una educación sexista generalizada: roles muy arraigados y una fuerte presión social para conservarlos. Hasta tal punto que las mujeres se sienten culpables ante la necesidad de libertad e independencia económica. Esta situación ha condicionado a muchas, sobre todo las de los grupos de edad más avanzados, dedicando toda una vida a las tareas del hogar, siendo esposas y madres, sin recibir ningún tipo de reconocimiento social. Así lo afirmaron los testimonios recogidos de las diferentes comarcas:

"En esta comarca hay muchas mujeres que no han trabajado nunca fuera del hogar o de la explotación familiar, ocupándose toda la vida de encargarse de los demás" (Mujer empresaria -37 años- núcleo rural).

En este sentido, a partir de nuestras investigaciones debemos potenciar a estas mujeres que no han trabajado nunca fuera del hogar y que no tienen una formación como las más jóvenes, pues disponen de un bagaje de trabajo doméstico y de educación de los hijos que suponen habilidades que es necesario recuperar porque pueden ser realmente útiles y transferibles al mundo laboral, este fue uno de los motivos por el que seleccionamos la variable edad a la hora de realizar las entrevistas en relación con la apertura de su propia empresa.

"Sí, pienso que esa capacidad que tienes de organizarte la puedes extrapolar a tu negocio y poder con la casa y mucho más, es decir, aprendes a organizarte el tiempo" (Empresaria -36 años- núcleo semiurbano).

"Sí, porque estas experiencias personales, ya sea limpiar, cuidar niños, pasar enfermedades graves, siempre ayudan en el terreno profesional, sobre todo a la hora de dar importancia a muchas cosas (...)" (Empresaria -35 años- núcleo rural).

\subsection{Infrarrepresentación}

Cuando analizamos la infrarepresentación de la población femenina, observamos como la conciliación de la vida familiar y laboral es actualmente un problema especialmente grave para la mujer por la dificultad de compatibilizar trabajo, promoción profesional, tiempo de ocio y maternidad, frenando así su capacidad de acción y, por lo tanto, haciendo latente su invisibilidad en todos los niveles de la vida social:

"Yo, personalmente, conozco a gente que trabaja a media jornada para dedicarse a las tareas del hogar. Es un rol que te adjudican por mucha igualdad que haya" (Empresaria -43 años- núcleo rural). 
No obstante, se debe insistir en la siguiente cuestión, en relación a las respuestas obtenidas: las mujeres han concebido el cuidado de los hijos como una obligación que sólo les pertenece a ellas, por lo que su actividad diaria cambia una vez que éstos abandonan el núcleo familiar, así pudimos constatar el segundo perfil de empresaria que decide abrir su empresa cuando sus hijas/os abandonan el núcleo familiar, precisamente, lo expresaron algunas de las entrevistadas pertenecientes a los intervalos de edad de 40 a 60 años:

Todos los días hago lo que hacen la mayoría de las mujeres; es que tengo la suerte que cuando decidí abrir mi negocio, mis hijos estaban estudiando fuera, sino, no hubiese podido (...)" (Empresaria -50 años- núcleo semiurbano).

En efecto, la maternidad, al igual que el cuidado del hogar, no debería ser exclusivamente una obligación o requisito de la mujer. En todo caso ha de interpretarse como una consecuencia negativa más de los patrones de socialización que hemos heredado del patriarcado, puesto que a las barreras y obstáculos iniciales para la contratación, debemos añadirles el temor de no poder desarrollar una carrera profesional en igualdad real de condiciones de trabajo, debido a la armonización de lo personal con lo familiar. Esta tendencia se acentúa en el mundo rural, ya que el carácter tradicional tiende a mantener los roles femeninos y masculinos más latentes, y ello hace que se infravalore la aportación real de la mujer.

\subsection{Discriminación directa e indirecta}

En la línea de todo lo expuesto, mujeres y hombres tienden a escoger las profesiones con las que más identifican su feminidad y masculinidad: es la llamada segregación horizontal del empleo. Existe la creencia, basada en estereotipos sexistas, de que hay profesiones femeninas y masculinas, o dicho de otro modo, profesiones para las que las mujeres o lo hombres tiene aptitudes "naturales" o "innatas", situación que perpetúa la discriminación directa en el mundo laboral, así lo expreso un alto porcentaje de las mujeres entrevistadas:

"Sí, porque hay bastante trabajo de electricista, fontanero, que realmente lo podría hacer una mujer, pero como está tan masculinizada la profesión, pues no lo hacen. Así, el hombre tiene un abanico más grande de posibilidades a la hora de poder elegir, pero la mujer no, sólo de cajera, dependienta (...) Bueno, luego están las que estudian fuera, que como es lógico, se van de aquí" (Empresaria -49 años- núcleo semiurbano).

De cualquier manera, el sentido tan arraigado de los trabajos asociados al género está cambiando y muestra una realidad en la cual la mujer aragonesa podrá realizar un trabajo asociado a la fuerza física o a actividades masculinas (como el de albañil o carpintero, entre otros), y un hombre, desempeñará tareas pertenecientes a la esfera reproductiva, como es el cuidado y la atención a personas, como hemos podido constatar en las entrevistas realizadas: 
"Cualquier tipo de negocio; no por ser mujer se tiene que dedicar a un sector determinado, por ejemplo, hacen falta guarderías, empresas de tareas domésticas que te fueran a limpiar, a comprar, a recoger a los niños al colegio, turismo, esto lo puede hacer lo mismo una mujer que un hombre" (Empresaria -44 años- núcleo rural).

Sumado a este aspecto, también constatamos la discriminación indirecta, se refuerza el hecho de que las diferentes entidades encargadas de gestionar los programas para la igualdad no atienden a las necesidades sociales e individuales de las mujeres, es decir, se produce una gran brecha entre las estructuras legales y los avances reales dentro de la sociedad; así lo constatamos en un los testimonios recogidos:

"Sí, saben muchas cosas sobre la igualdad por la tele y a nivel laboral y porque lo ves día a día, pero sobre feminismo poco, igual que yo (...), además tampoco luchan mucho por ello" (Empresaria -32 años- núcleo semiurbano).

"Pues me imagino que si gestionan las subvenciones algo sabrán; también te digo que es una falta de interés tanto por parte de las personas que se encargan de las subvenciones como de las usuarias de las mismas (...)" (Empresaria -49 años- núcleo semiurbano).

En esta línea, podemos decir que para dar lugar a una avance real de los postulados feministas desde estas posiciones institucionales y de su colaboración (cuando se produce), con el tejido feminista asociativo, se necesita la ocupación de puestos de responsabilidad por personas feministas.

\subsection{Identificación de la falta de población femenina}

En la etapa actual, cuando las mujeres han podido acceder a una formación profesional cualificada no se ha producido su fijación en el medio rural, salvo en las cabeceras comarcales o núcleos semiurbanos y urbanos. Pero, es obvio que no todas las jóvenes rurales adquieren una formación superior, por lo tanto, en esta huida hacia ciudades más grandes sigue influyendo la búsqueda de una mayor independencia y libertad por parte de las mujeres, sumado a la falta de oportunidades en el medio rural y los valores tradicionales asociados al género, tal y como expresan nuestras informantes más jóvenes y queda ilustrado en la siguiente respuesta:

"Las diferencias sociales en el medio rural están más marcadas en lo que se refiere a hombres y mujeres. También influye mucho la educación, por ejemplo, en mi casa han sido machistas, yo ponía la mesa y mis hermanos a trabajar fuera; también a la hora de salir, te dejan salir menos porque eres chica (...). Yo creo que en una ciudad te sientes más libre y, por eso, las mujeres se van" (Empresaria -28 años- núcleo rural). 
Además, el más fácil acceso masculino al mercado laboral en las zonas rurales ha dado lugar a que las chicas jóvenes emigren a las ciudades, como señalan las mujeres entrevistadas, aspecto que propicia la masculinización del medio rural aragonés:

"La chicas jóvenes no piensan en quedarse aquí toda la vida, más que nada, por la gente, por los roles, porque aquí no tienes una salida" (Empresaria -29 años- núcleo semiurbano).

Asimismo, a la pregunta relacionada con la perspectiva de abandonar su núcleo de origen, es decir, sobre si han pensado alguna vez en marcharse de su comarca o su localidad a trabajar a otra parte, un alto porcentaje de mujeres rurales contesto que sí, a diferencia del grupo compuesto por mujeres que pertenecen a las respectivas capitales de provincia, que dijo que no habían pensado nunca en abandonar sus diferentes ciudades, aunque muchas del primer grupo ya se fueron para realizar sus estudios, pero decidieron volver para asentarse y formar una familia. Esta situación puede apreciarse en los ejemplos que se exponen a continuación:

"Ś́, muchas veces he querido volver a Barcelona, porque este pueblo agobia, tienes ratos libres y no sabes que hacer... La verdad que no existe una oferta cultural muy amplia" (Empresaria -41 años- núcleo rural).

"La verdad, estuve fuera trabajando y luego volví, porque hay una edad que no te gusta el pueblo, pero cuando quieres formar una familia lo valoras mucho más" (Empresaria -45 años- núcleo rural).

\subsection{Aspectos positivos y negativos}

Las mujeres entrevistadas muestran una idea clara sobre lo que significa la igualdad de género, pero también señalan que los valores culturales patriarcales están muy arraigados en la sociedad aragonesa, sobre todo en el mundo rural, pues las personas los tienen muy asumidos, tanto, que muchas no se los cuestionan, como señala esta empresaria:

"La igualdad de oportunidades entre hombres y mujeres en todos los niveles de la vida, ni lo femenino extremo, ni lo masculino extremo. Pero aquí, hay mucha gente que no se cuestiona esto, las mujeres se quedan en casa y punto, mientras que los hombres son los que traen el dinero" (Empresaria -41 años- núcleo semiurbano).

No obstante, hoy por hoy, podemos afirmar que se aprecia un salto generacional a la hora de asumir tareas, como podemos observar en las respuestas de la población femenina entrevistada, que no tienen ya como referencia principal el ámbito doméstico. Cabe destacar que este porcentaje está influido fundamentalmente por la edad, pues pertenecen al sector más joven de las entrevistadas, es decir, las que se encuentran en edades comprendidas entre 20 y 40 años: 
"En mi casa, aparte de la empresa de bordados tengo otra de distribución industrial, también soy perito, trabajo para tres empresas dentro de la provincia. No hago nada en casa (...)" (Empresaria -38 años- núcleo rural).

Sin embargo, la visión de las mujeres en las diferentes provincias no ha permanecido estancada. Las mujeres aragonesas a menudo saben identificar bien los recursos y las necesidades locales que pueden convertirse en mercados potenciales; de esta manera, el sector servicios se convierte en el gran aliado de las mujeres emprendedoras entrevistadas, apostando por empresas tales como comercialización de productos tradicionales a nivel nacional e internacional, servicios a la población, especializados o no, residencias de ancianos, guarderías, casas cuna, empresas de ayuda a domicilio, centros de relajación, tintorerías, agricultura ecológica, turismo rural y empresas dedicadas al ocio, relacionadas con la aventura y el turismo rural, donde la variable del lugar cobra importancia.

"Yo hubiese montado algo, pero no una tienda, algo innovador, ampliando la gama de servicios a la población" (Empresaria -40 años- núcleo rural).

"Cualquiera de cara al turismo, como pueden ser las casas rurales, rutas, deportes de aventura"... (Empresaria -42 años- núcleo rural).

"Una residencia privada, pero no como un sitio para dejar a los abuelos, sino algo diferente. O una tintorería" (Empresaria -32 años- semiurbano).

"Un sector a desarrollar sería el de la agricultura ecológica, turismo rural. Sobre todo en agricultura y servicios, en el sector de transformación y artesanía. También, muchas cosas que las mujeres han hecho en casa, sacarlas para explotarlas comercialmente: repostería, conservas" (Empresaria -29 años- semiurbano).

No obstante, un pequeño porcentaje opinan que la agricultura y ganadería, la construcción, fontanería o, lo que es lo mismo, sectores tradicionalmente masculinos, se presentan como mercado potenciales para terminar con los roles tradicionales de género, sobre todo en lo que al mundo rural se refiere:

"Conozco a una chica que tiene una empresa de construcción y otra que es fontanera. Hoy en día, si realmente te gusta y lo haces bien, no existen diferencias. Pero, aun hoy, existen diferencias, más que nada, el hablar por hablar en los pueblos es algo habitual" (Empresaria -35 años- núcleo semiurbano).

"Ahora conocemos a una chica emprendedora que es ganadera y agricultora, además le va bastante bien (...). Es un poco la mentalidad que se tiene a la hora de hacer las cosas" (Empresaria -47 años- núcleo semiurbano).

Sumado a esto, las informantes reclamaron generalizar el uso de Internet como herramienta de desarrollo personal y profesional de las mujeres, situación que debe mejorar en los pueblos más pequeños y con peor acceso a las comunicaciones. Así, las entrevistadas, piensan en el teletrabajo como la mejor opción: 
"Cualquiera, hace cinco años, no. El vuelco de acceso a internet te hace tener expectativas de lo que sea, da igual estar aquí o en Madrid, con la ventaja de que aquí tienes toda la tranquilidad" (Empresaria -33 años- núcleo rural).

No obstante, las mujeres que viven en pequeñas poblaciones rurales se inclinan por la apertura de comercios tradicionales, como por ejemplo, panaderías, supermercados y tiendas de ropa. Asimismo, inciden en que la mayoría de estos servicios deberían ser itinerantes para llegar a los pueblos más pequeños, pues presentan un gran déficit, tanto en lo relacionado con los servicios básicos para la población como en el comercio:

"Una lavandería, una panadería, el futuro es itinerante. Los pueblos son muy pequeños y no tienen servicios, no hay panaderías, por lo que repartir pan es buena opción en estos núcleos tan pequeños, también lo mismo a nivel de charcuterías (...), pocos servicios pero de cosas sencillas (...)" (Empresaria -40 años- núcleo semiurbano).

También, la diversificación de actividades en las provincias necesita, más que nunca, a las mujeres depositarias de los saberes y habilidades necesarias para revalorizar y potenciar los productos agroalimentarios, la gastronomía, las tradiciones culturales, el turismo rural, etc. En este sentido, el agroturismo, los trabajos manuales, la agroindustria alimentaria, puede ser la mejor alternativa laboral para las mujeres de grupos de edad más avanzados que no han tenido acceso a la formación y que han esperado a que sus hijos abandonen el núcleo familiar, tal y como expresan las entrevistadas. El resto no lo tiene muy claro o piensa que el sector servicios puede ser una buena opción, pero no se decantan por ningún tipo de actividad a desarrollar. Cabe destacar que algunos de estos sistemas locales están creciendo y diversificando su propia actividad. Por ejemplo, esto se aprecia en el desarrollo del turismo rural y la comercialización de productos tradicionales, como la elaboración de mermeladas y la apicultura en el Somontano de Barbastro, la trufas en Teruel o la viticultura en las comarcas de Zaragoza, entre otras, a lo que ya se ha hecho referencia.

"Creo que la opción es bastante variada para las mujeres de esta franja de edad, casas rurales, restaurantes, agroindustria alimentaria, pequeñas tiendas con productos tradicionales hechos en casa" (Empresaria -51 años- nucleo rural).

De esta forma, la incorporación de las mujeres al mercado de trabajo ha supuesto cambios importantes a otras escalas, desde la necesidad de nuevas políticas de conciliación laboral y familiar hasta una mayor igualdad en los roles establecidos. En este sentido, la situación laboral de las mujeres aragonesas ha experimentado un gran cambio en la sociedad, como se deduce de las respuestas:

"Por supuesto, la mujer ha tenido un papel importante en todos los pueblos aún estando en la retaguardia. Luego, con la apertura de pequeños negocios han sabido ir abriéndose el camino" (Empresaria -35 años- núcleo semiurbano). 
Aunque muchas de ellas piensan que a las mujeres les queda un largo camino por recorrer para optar y llegar a tener las mismas condiciones de trabajo que la población masculina:

"Muchas leyes, pero todavía en las entrevistas de trabajo te preguntan si estas casada o tienes pareja, que sí quieres tener hijos pronto, que en esta empresa no hay reducción de jornadas, que muchas veces hay que hacer horas extras (...)" (Empresaria -29 años- núcleo semiurbano).

Esta situación puede ser debida a la falta de noción sobre feminismo, debido a una ausencia de formación e interés por el tema, o por el sentido injustificado de equiparar feminismo a machismo y ginocentrismo, tal y como podemos comprobar en las entrevistas realizadas:

"Yo equiparo el feminismo al machismo, es como si las mujeres fuésemos superiores (....)" (Empresaria -34 años- núcleo semiurbano).

"Yo creo en la igualdad, no en que la mujer sea mejor que el hombre (...)" (Empresaria -46 años- núcleo urbano).

Finalmente, el autoemplearse es un tema recurrente para las mujeres, pues puede darse en cualquier actividad económica de nuestra sociedad, independientemente de la cualificación, sexo y localización geográfica. En la medida en que la mujer se capacite, mejore su autoestima y sus valores, como han mostrado todas las entrevistadas, accederá a nuevas oportunidades de superación, como se desprende de las respuestas seleccionadas a modo de ejemplo, sobre la pregunta relacionada con los cambios sociales y personales que ha supuesto emprender en femenino.

"Todo aquello en lo que crea y tenga ganas de hacerlo. Al final, es siempre ilusión" (Emprendedora -36 años-).

\subsection{Actividades emprendimiento femenino}

La propia decisión de las mujeres y el apoyo de las instituciones públicas han propiciado el aumento de emprendedoras, ocupando los siguientes porcentajes por sectores de actividad, tal y como se ha constatado a través del análisis de las mujeres entrevistadas, datos que presentamos en la siguiente tabla.

La proporción de mujeres en el sector servicios y comercial puede encontrar su explicación en que las emprendedoras crean su empresa en aquellos sectores en los cuales tienen cierta experiencia por su adscripción de género. También se aprecia un crecimiento de las actividades de servicios personales debido a veces a un inferior desembolso económico en los comienzos del negocio, ya que muchas de estas activi- 
dades se pueden trabajar desde el domicilio particular, permitiendo conciliar vida personal y profesional, tal y como constatamos a través de la entrevistas realizadas a las mujeres empresarias.

Tabla 3. Empresas femeninas por sectores de producción

\begin{tabular}{|l|c|}
\hline Sectores & Entrevista \\
\hline Sector servicios & $83,57 \%$ \\
Turismo rural & $8,19 \%$ \\
Hosteleria y Hoteles & $3,27 \%$ \\
Servicios a la población & 36,06 \\
Servicios a las empresas & 24,59 \\
Servicios profesionales (profesiones liberales) & $4,91 \%$ \\
Arte (restauración, producción, promoción, difusión y venta): & $6,55 \%$ \\
Comercio & $11,47 \%$ \\
\hline Construcción & $3,27 \%$ \\
Industria & $19,67 \%$ \\
Agricultura y ganadería & $3,27 \%$ \\
\hline
\end{tabular}

Fuente: Entrevistas realizadas, elaboración propia.

También es necesario poner de relieve la importancia que adquiere el espacio geográfico en relación con el contexto socioeconómico, a la hora de entender el tipo de negocio por el que han optado las mujeres. En este sentido, las características físicas del territorio, han permitido, justamente, que en Huesca el medio físico ofrezca más oportunidades para crear empleo que en el resto de provincias aragonesas, en lo que a mundo rural y su relación con la explotación de recursos naturales y la cultura del ocio se refiere, por la importancia que tienen los Pirineos, lo que explica en buena medida la elección personal de nuestras emprendedoras a la hora de abrir su negocio; a esto se añaden los servicios para atender las necesidades básicas de la población, evitando su marcha a ciudades o cabeceras comarcales cercanas. No obstante, las características de la parte meridional de la provincia oscense tienen otras connotaciones menos turísticas, aunque también algunas de esas empresas se han implantado allí. Es aquí donde están los núcleos de población más grandes, como son Huesca, Barbastro, Monzón o Fraga. Si nos centramos en Los Monegros, que presenta la mayor despoblación en los pueblos pequeños de esta zona, es destacable también la cantidad de comercios que se han creado en municipios cuyos negocios de este tipo estaban a punto de cerrar, lo que hubiese supuesto un grave perjuicio para los habitantes, que hubieran tenido que desplazarse a poblaciones vecinas para conseguir productos básicos. Tam- 
bién, en esta parte de la provincia, nos encontramos con artesanas tanto alimentarias como no alimentarias; se han creado puestos de trabajo para la mujer en sectores tan variados como la elaboración de juguetes tradicionales aragoneses, de objetos decorativos, de regalo, de diseño o reciclaje de joyas y plata... Dentro de los productos alimentarios contamos con promotoras dedicadas a la fabricación de quesos de oveja, un taller artesano de transformación y comercialización de frutas y hortalizas, envasado y comercialización de vino ecológico, entre otras.

Cuando nos adentramos en Zaragoza capital, al igual que en el resto de capitales de provincia aragonesas, es también el sector servicios lo que prima entre las emprendedoras. En lo que respecta a las comarcas zaragozanas, hay sectores industriales como la viticultura, sobre todo en el Campo de Borja y Cariñena, zonas con vinos de denominación de origen protegida, en los que las mujeres se están abriendo paso en un contexto que ha sido siempre claramente masculino; Además, existe una demanda creciente para la salud y el bienestar, donde las nuevas empresarias ofrecen servicios que no ofrece el sistema público, como desarrollo personal, entre otros. El análisis de la muestra nos dice que son en su mayoría mujeres que estas interesadas en estas áreas y que se han instruido a través de la formación privada y cursos públicos. También existen los llamados comercios alternativos, como el Comercio de Ayer y de Hoy, inscrito en el marco del proyecto de Dinamización del Casco Histórico de Zaragoza, en el que la mayoría de las emprendedoras son mujeres.

En la provincia de Teruel difiere también la forma de emprender en las diferentes comarcas y en la capital: mientras que, por ejemplo, en Calamocha y Teruel priman los servicios a la población, si nos ubicamos en plena Sierra de Albarracín, la artesanía cobra importancia a la hora de emprender en femenino a través de la cerámica típica del lugar. No obstante, se multiplican cada vez más las posibilidades de encontrar un empleo en el sector turístico debido a la reciente explotación del patrimonio cultural de esta comarca; pero también la agricultura se presenta como alternativa a través de la industria vinculada a los productos típicos de la zona o con DO.

Y, por último, se constata que la industria, la agricultura-ganadería y la construcción siguen representando un porcentaje muy pequeño de actividad confirmando los roles y estereotipos patriarcales ligados al mercado laboral.

\subsection{Tiempo libre o de ocio}

En relación con este tema, podemos afirmar, en primer lugar, que a pesar de la mayor incorporación de las mujeres aragonesas al mercado laboral todavía hoy se aprecia una división por sexo en las provincias en cuanto al empleo del tiempo en las actividades diarias que confirman las entrevistas. Por esta razón, a pesar de los avances registrados en nuestra sociedad, la división de roles continua presentando claros indi- 
cios de una discriminación por género en las actividades del hogar, como expresaron las entrevistadas a la hora de describir su ritmo de vida:

"Me levanto, me organizo con el crío y la casa, hasta que llega la persona que se encarga de cuidarlo. Si una mañana te toca venir a la residencia, llegas aquí, luego igual te tienes que ir con una persona al hospital, más tarde hacemos nuestros cambios de información sobre la residencia, hago papeles y luego me voy a casa a disfrutar de mi familia. Cuando me toca por la tarde, es igual. Solo tenemos diez días al año de vacaciones" (Empresaria -31 años- núcleo semiurbano).

A la pregunta referida a la dedicación del tiempo libre o, lo que es lo mismo, a describir su ritmo de vida una vez terminado el trabajo productivo y reproductivo, la gran mayoría de las mujeres entrevistadas lo dedican a actividades culturales o como asociadas:

"Mi vida ahora es un poco locura, me levanto, organizo papeles y la casa, espero a la chica que viene a casa y le digo un poco lo que tiene que hacer, me voy al bar, organizo a las camareras, voy a comprar lo que hace falta y vuelvo al bar otra vez (...). Bueno, muchas de estas cosas las hago con mi hijo, excepto los fines de semana que cierro el bar y me dedico a estar con mi familia y a pintar y a restaurar. Algunos días por la tarde, si me queda tiempo, voy a la asociación, pero pocos. Aunque, siempre he pensado en la igualdad en casa con mi pareja, te das cuenta de que las mujeres tenemos otra capacidad a la hora de ocuparnos y organizar todo, más cuando eres empresaria, porque te cargas con todo a la espalda: el hijo, la casa, el negocio (...)" Empresaria -35 años- núcleo semiurbano).

Mientras, sus respectiva parejas señalan que lo dedican a actividades que no suponen ningún tipo del estrés que supone querer llegar a todo, puesto que en la mayoría de los casos no dedican ni un minuto de tiempo a las tareas domésticas o reproductivas, aunque hay que decir al respecto que las mujeres son las primeras en reforzar estos comportamientos, porque como ya hemos dicho, muchas de ellas no se los cuestionan. Esta situación, desemboca en actos de la vida cotidiana en los que el hombre muestra su superioridad o poder frente a la mujer y que nos alejan de la igualdad. Sobre la dedicación del tiempo libre de su pareja, responden:

"Pues a ver la tele en casa, vamos, a descansar, a estar en el bar con los amigos viendo el fútbol..." (Empresaria -51 años- núcleo urbano).

A partir de los testimonios recogidos, podemos decir que este grupo de micromachismos se apoyan en la idea de que el tiempo es posesión masculina: el varón crea tiempo de descanso o diversión a costa de la sobrecarga laboral de la mujer (por ejemplo, utilizar el fin de semana para "sus" aficiones, o postergar su llegada a casa después del trabajo) y como dice Bonino (2004:3), esto tiene como efecto que, en promedio, los varones tengan más tiempo libre que las mujeres (y a costa de ellas). 


\subsection{Identificación y valoración de las redes}

Algunos de los objetivos de este trabajo se orientaban a constatar la percepción que tienen las mujeres de su propia capacidad para crear empresas, así como del papel que le asignan a las políticas públicas como apoyo o estímulo a las emprendedoras, la capacidad de asociación que han desarrollado y el papel que juega este capital social. Varias de las preguntas a las entrevistaban tenían ese fin, como puede verse en el anexo.

A la pregunta de si creen que hay emprendedoras en sus provincias, el total de las entrevistadas contestó que sí, que actualmente nos encontramos ante muchas mujeres con iniciativa propia para montar un negocio. Si ahora nos centramos en la apertura de empresas femeninas a partir de las diferentes iniciativas públicas, la mayoría de las entrevistadas mostró su conocimiento sobre las políticas orientadas a estos fines, mientras que un escaso porcentaje coincidieron en no conocer los logros de este tipo de programas. Como ejemplo de ambas posturas se transcriben las siguientes respuestas:

"Sí que conozco algunas, tanto Leader como Equal han sido muy importantes para el desarrollo de empresas femeninas" (Empresaria -50 años- núcleo semiurbano).

"No los conozco a fondo, no puedo opinar. Lo que creo es que este tipo de proyectos, por lo menos, te incita hacer algo" (Empresaria -36 años- núcleo semiurbano).

Asimismo, la mayoría de la población femenina entrevistada, perteneciente a zonas rurales, está de acuerdo en que estas iniciativas han sido el empujón que necesitaban para que muchas mujeres se decidieran por la creación de un negocio propio. También aseguran que las iniciativas para el desarrollo rural, LEADER y PRODER, han abierto nuevas expectativas a nivel laboral, tanto a hombres como a mujeres. Sin embargo, de la misma manera inciden en la necesidad de subvencionar áreas que aseguren puestos de trabajo para el futuro asentamiento de las personas en las diferentes comarcas, para lo que es importante hacer un estudio previo, pues sino pueden resultar inútiles tales subvenciones, tal como expresa la siguiente cita:

"Sí, aquí en algunas comarcas, como Los Monegros, han optado por subvencionar actividades que no se desarrollaban, pero no había demanda y tuvieron que dar subvenciones a otras actividades. Lo que hay que subvencionar son áreas que creen puestos de trabajo" (Empresaria-56 años- núcleo semiurbano).

También, a nivel urbano, un alto número de las mujeres entrevistadas, pertenecientes a las capitales provinciales, reconocen que si no existiera el Programa Infoempresarias del Instituto de la Mujer, la Cámara de Comercio con el PAEM o determinadas asociaciones dedicadas al empresariado femenino, como ARAME, o al empresariado en general, como el CEPYME, este tipo de ayudas permanecerían invisibles para la población.

"Pues se conocen las ayudas gracias al Instituto de la Mujer y a la Cámara de Comercio a través de su programas dedicados a informar al empresariado; también exis- 
ten asociaciones dedicadas al empresariado en las que las mujeres podemos informarnos de lo que conlleva abrir tu propio negocio, ya sea ARAME o el CEPYME" (Presidenta Asociación de Empresarias de Aragón).

En lo que se refiere a la creación de redes entre las empresarias, los resultados obtenidos a este respecto revelan que, a nivel particular, un importante porcentaje de empresarias parecen ser conscientes de la necesidad de colaboración y creación de redes. Sin embargo, a nivel empresarial esta conciencia parece no existir, ya que más de la mitad de las empresas estudiadas no han establecido ningún acuerdo de colaboración Inter-empresarial, aunque cabe destacar que muchas colaboran ocasionalmente con entidades locales. Tampoco parecen existir acuerdos de este tipo en la producción y oferta de servicios conjuntos y en la comercialización de sus productos, salvo en lo que se refiere a las ferias destinados a la producción y difusión de los relacionados con las diferentes D.O. o con los diversos sectores de producción, si bien los porcentajes de participación referidos a esta cuestión son reducidos.

"No tengo redes con otras, pero creo que algunas se juntan en las ferias de DO para comercializar sus productos" (Empresaria -39 años- núcleo rural).

Pero algunas mujeres inciden en que las actividades impartidas a través de estas entidades deberían centrarse en la formación para, posteriormente, desempeñar puestos de trabajo, pues son muchas las mujeres que no se pueden permitir su propio negocio. Como propuesta prioritaria destaca las clases para el carnet de conducir para todo tipo de vehículos (camiones, autobuses...). Así opina esta empresaria sobre esas iniciativas:

"Yo creo que deberían emprender mucho más, porque hay mucha gente que está acomodada y no luchan por las necesidades de la población. Un obstáculo de estas asociaciones es el de la formación para el desempeño de un puesto de trabajo fijo, porque hay mujeres que no se pueden permitir ser autónomas" (Empresaria -42 años- núcleo semiurbano).

Sumada a estas propuestas, la impartición de cursos de formación y los encuentros de mujeres emprendedoras a través de grupos de reflexión, son las iniciativas que deberían realizar los diferentes organismos públicos para concienciar realmente sobre la igualdad de género a través de teoría y práctica feminista a las mujeres en las diferentes provincias, tanto a nivel urbano como rural; así lo confirmaron las entrevistadas:

"Cursos de formación (igualdad de género, tecnologías...), encuentros entre mujeres emprendedoras a través de grupos de reflexión. Todo esto para tener conciencia plena sobre la igualdad, porque si no se queda todo en el tintero" (Empresaria -32 años- núcleo urbano).

No obstante, también señalan que uno de los precedentes para el cambio ha sido las diferentes jornadas para mujeres emprendedoras realizadas en estos últimos años, 
tanto a nivel provincial como local, pues han servido de ejemplo y empujón para muchas otras, ya que compartir su experiencia como empresarias, ha reforzado los primeros pasos a dar para la igualdad de género en el plano familiar y laboral, además del asesoramiento e intercambio de ideas para la apertura de negocios en el medio estudiado:

"Las jornadas de las mujeres emprendedoras, que sirven un poco para concienciarnos de todo lo que podemos hacer, de ofrecernos formación (...)" (Empresaria -42 años- núcleo semiurbano).

En relación con la influencia del movimiento asociacionista femenino aragonés, las entrevistadas están de acuerdo en que a partir de las diferentes asociaciones, tanto de las mujeres empresarias como de cualquier otra, como puede ser la de Amas de Casa en las poblaciones rurales o las Asociaciones de Vecinos o de Barrios en las capitales de provincia, su situación ha cambiado o puede cambiar, puesto que las mujeres empiezan a salir de sus casas, crean redes con otras mujeres y otras asociaciones, es decir, se informan unas a otras sobre las diferentes actividades y propuestas que se realizan, con el fin de establecer alianzas a nivel personal y social para la consecución de la igualdad de derechos de la ciudadanía. Apoyadas por estas asociaciones, se han acercado a las nuevas tecnologías, como es Internet, y, sobre todo, se han informado sobre la situación de la mujer en todos los niveles, social, político, económico y laboral.

"Sí, ha influido mucho, porque se han encargado de formar e informar, han creado el día Internacional de La Mujer, también diferentes jornadas sobre las mujeres emprendedoras de la provincia en plan de protocolo y apoyo" (Empresaria -41 añosnúcleo semiurbano).

"Pues es que todo tipo de entidad que saque a la mujer de casa está bien, porque muchas se quedan estancadas en cuidar a los hijos, luego a los nietos (...). Las asociaciones de barrio o de mujeres están muy bien, ofrecen talleres de manualidades, charlas sobre conciencia ciudadana e igualdad de género, entre otras cuestiones" (Empresaria -39 años- núcleo rural).

\section{Conclusiones}

El análisis que se ha llevado a cabo en el trabajo para ir alcanzando los objetivos previstos permite tanto verificar la hipótesis, aunque sea parcialmente, como poner de relieve lo que todavía queda por hacer. De esta manera, las conclusiones vienen complementadas con algunas estrategias destinadas a evitar los problemas demográficos, laborales y sociales que se desprenden de la desigualdad de género en Aragón.

Primeramente, se constata que el perfil dominante de emprendedora aragonesa es el de una mujer de 30 a 40 años con hijos a su cargo, cuyo núcleo de origen es el mu- 
nicipio en el que ha abierto su empresa; la mayoría cuenta con estudios universitarios (ya sea diplomatura o licenciatura). En intervalos de edad de 40 a 50 años presentan las mismas características, pero el porcentaje es menor, además deciden abrir su empresa cuando sus hijos han abandonado el núcleo familiar.

A la hora de detectar las dificultades habituales que han afectado a estas mujeres a la hora de abrir su negocio, pudimos comprobar cómo las mujeres rurales tienen que sobrepasar barreras patriarcales más rígidas que las mujeres urbanas, tanto a la hora, de la discriminación por género, como a causa de la escasez de recursos para la conciliación familiar y laboral. Esta situación se hace más visible, en poblaciones de pequeñas dimensiones ya que sigue presente la idea de que las mujeres son esposas y madres, y estos dos papeles constriñen tanto la vida privada de estas mujeres como su presencia y comportamiento público. No obstante, la visión de las mujeres rurales no ha permanecido estática, pues la apertura de sus negocios y un mayor nivel de formación han supuesto cambios tanto a nivel personal, como social y político.

También, se pone también de manifiesto la infrarrepresentación de las mujeres en todos los niveles de la vida social, ya que todavía falta mucho para que se consiga una verdadera igualdad de oportunidades y la actividad femenina repercuta con mayor intensidad en el desarrollo local, ya que persisten rasgos patriarcales, como son los estereotipos asociados a la división de género, la segregación horizontal y diferentes tipos de micromachismos ligados a la vida diaria, como es la utilización del tiempo, que hacen que la población femenina siga subordinada al género masculino. De esta forma, la apertura de su propio negocio sigue siendo para muchas la solución ante la conciliación entre la vida familiar y laboral.

Si ahora nos centramos en la discriminación directa, podemos afirmar que todavía existe un sentido muy arraigado de los trabajos asociados al género, así, la realidad nos muestra que una mujer tendrá muy difícil acceder a un trabajo asociado a la fuerza física (como el de albañil, soldador o mecánico) o con actividades masculinizadas y un hombre no desempeñará habitualmente tareas pertenecientes a la esfera reproductiva. No obstante, pese a todo lo dicho, se da la singularidad de que cada vez son más las mujeres que se dedican a labores tradicionalmente masculinas, como puede ser la agricultura, la construcción o la fontanería, sobre todo las de intervalos de edad más jóvenes.

Sumado a esto, la población femenina que ha decidido abrir su negocio no ha sufrido ningún tipo de discriminación indirecta a la hora de pedir ayuda en los diferentes organismos públicos por el hecho de ser mujer, lo que permite apreciar un cambio en la mentalidad patriarcal clásica, si bien se comprueba, igualmente, que siguen existiendo pruebas de micromachismos, ya que este apoyo no implica la división paritaria de las tareas domésticas y la apertura de negocios en sectores masculinizados. De esta forma, a menudo se habla de feminismo desde actividades muy dependientes de subvenciones, vinculadas a las burocracias políticas, pero existe una falta de formación de las per- 
sonas encargadas de gestionar dichos proyectos que desemboca en una falta de interés por parte de las usuarias y, por lo tanto, una homogenización del grupo que deja de lado los intereses y necesidades individuales de las usuarias. Una vez analizadas estas cuestiones, de las entrevistas se deduce que las empresarias creen que la impartición de cursos de formación y los encuentros de mujeres emprendedoras a través de grupos de reflexión, son las iniciativas que deberían realizar los diferentes organismos públicos para concienciar realmente sobre la igualdad de género a las mujeres en las diferentes provincias, tanto a nivel urbano como rural, donde también debe cobrar importancia el uso de las nuevas tecnologías a la hora de abrir un negocio.

En relación con la falta de población femenina en el mundo rural, hemos podido constatar cómo el mundo rural aragonés se caracteriza por su escasa oferta de empleo para las mujeres y la que existe destaca por ser sexista y no estar acorde con la expectativas individuales, por lo que las mujeres jóvenes tienden a emigrar a las ciudades en busca de un puesto de trabajo cualificado y de una plena realización personal, en cuanto a roles y estereotipos de género se refiere, pero muchas de ellas vuelven para asentarse y formar una familia.

Respecto a los aspectos positivos, la mayoría de las mujeres entrevistadas muestran una idea clara sobre la igualdad de género, pero la población femenina perteneciente a áreas rurales incide en el hecho de que los valores relacionados con la feminidad y masculinidad están muy arraigados todavía en la sociedad rural actual, pues las personas los tienen muy asumidos, tanto que no se los cuestionan.

Pero, las mujeres emprendedoras, a menudo saben identificar bien los recursos y las necesidades locales que pueden convertirse en mercados potenciales. De esta manera, el sector servicios se convierte en el gran aliado de las mujeres emprendedoras entrevistadas. Aunque, la elección por la apertura de una determinada empresa sigue confirmando que los roles socialmente admitidos contribuyen a que las mujeres emprendedoras sepan aprovechar aquello para lo que tradicionalmente se las ha preparado, lo que sigue consagrando la división horizontal. Sumado a esto, el agroturismo, los trabajos manuales o la agroindustria alimentaria mediante la elaboración de productos tradicionales puede ser la mejor alternativa laboral para las mujeres de grupos de edad más avanzados, que no han tenido acceso a la formación y que han esperado a que sus hijos/as abandonen el núcleo familiar.

En cuanto al uso del tiempo, se confirma que mientras la mayor parte del trabajo masculino se basa en el ámbito productivo, las mujeres dividen su tiempo entre la casa y su negocio. Además, mientras que los hombres se divierten de manera relajada, una vez terminado el trabajo productivo; las mujeres, lo disfrutan cuando finalizan todas sus tareas, tanto las productivas, como las reproductivas, muchas veces con el estrés que supone llegar a todo. Sumada a esta cuestión, la mayoría de las entrevistadas utilizan su tiempo de ocio como capital social a través del movimiento asociacionista, en asociaciones dedicadas a empresarias, a amas de casa o con fines sociales. 
A la hora de identificar las redes y las características de las actividades laborales que desarrollan, parece que, a nivel particular, un importante porcentaje de empresarias son conscientes de la necesidad de colaboración y creación de redes. Sin embargo, a nivel empresarial esta conciencia no se ha desarrollado lo suficiente, habida cuenta de que más de la mitad de las mujeres entrevistadas no ha establecido ningún acuerdo de colaboración interempresarial.

Finalmente, se pone de manifiesto la ignorancia que las encuestadas muestran sobre cuestiones feministas, por lo que se debería integrar en las actuaciones a desarrollar la propuesta de formación en feminismo. Este aspecto supone facilitar a las mujeres herramientas para el análisis de la realidad en sus más diversos aspectos, desde una perspectiva de género.

\section{Anexo: Item entrevista}

- Nombre, edad, estatus (casada, soltera....):

- Si es casada (o separada), número de hijos y edad de los mismos:

- Lugar de residencia (pueblo, cuyo tamaño puede influir en su situación):

- Lugar de nacimiento y, en su caso, tiempo que lleva viviendo en ese pueblo:

- Estudios:

- Año de creación empresa:

- ¿Qué dificultades a nivel social (laborales, de convivencia, de hacer vida social) crees que tienen las mujeres en tu comarca o en tu localidad?

- ¿Crees que los chicos jóvenes lo tienen más fácil para acceder al mercado laboral? ¿Crees que esta situación (más fácil acceso masculino al mercado laboral) ha dado lugar a que las chicas jóvenes emigren a las ciudades (a Huesca, Zaragoza u otras localidades) y cada vez sean menos en el medio rural?

- ¿Crees que las mujeres y hombres tienden a escoger las profesiones con las que más identifican su feminidad y masculinidad?

- ¿Crees que en tu localidad hay muchas mujeres que no han trabajado nunca fuera del hogar o de la explotación familiar (como agricultoras o ganaderas)?

- ¿Has pensado alguna vez en marcharte de tu localidad a otra parte? 
- Desde tu experiencia, ¿siguen siendo las mujeres en tú localidad las que se encargan de las tareas reproductivas aunque se dediquen a otra actividad?

- ¿Crees que el bagaje de trabajo doméstico y de educación de los hijos suponen habilidades o potencialidades que pueden ser realmente útiles y transferibles al mundo laboral?

- ¿Qué tareas sueles realizar todos los días? ¿Me podrías describir el ritmo de vida diario, con horarios a ser posible?

- ¿Crees que la incorporación de las mujeres aragonesas al mercado de trabajo ha supuesto cambios a otras escalas (sociales y personales)?

- ¿Para ti qué significa la igualdad de género?

- ¿Crees que existen diferencias entre las mujeres de las capitales provinciales y de las diferentes comarcas en lo que concierne a los roles y estereotipos de género?

- ¿A qué te dedicas?

- ¿Recibiste el apoyo de tu familia cuándo decidiste abrir tu propio negocio?

- ¿Te has encontrado con dificultades a nivel local para llevar a cabo tu proyecto por ser mujer?

- ¿Habéis formado alianzas con otro tipo de instituciones o proyectos?

- ¿Crees que hay emprendedoras en Aragón, ? (en tu pueblo, ciudad o en otros que conozcas: mujeres con iniciativa para montar un negocio propio)

- ¿Qué tipo de empresas o negocios crees que puede montar una mujer en tu localidad?

- ¿Crees que las mujeres empresarias tienen conocimiento y sensibilidad hacia las políticas de igualdad de género a través de los diferentes grupos de acción local o mediante otras acciones de diferentes entidades tanto públicas, como privadas destinadas a las mismas?

- ¿Qué iniciativas a nivel rural y urbano deberían realizar estos organismos para concienciar realmente sobre la igualdad de género a las mujeres tanto a nivel urbano como rural?

- ¿Crees que a partir de estas iniciativas la situación de la mujer ha cambiado o puede cambiar? (En primer lugar, nos referimos a las iniciativas llevadas a cabo a nivel empresarial y a las que han contestado en la pregunta anterior. En segundo lugar, no sólo nos referimos al nivel laboral, sino a todos los niveles de la vida social desde una perspectiva de género. 


\section{Bibliografía}

Beecheey, V. (1999) The sexual division of labour an the labour process: a critical assesmente of Braverman". En Stephen Wood: The degradation of work?, skill, deskilling and the labour process. London, Hutchison.

Bonino, L. (2004) La violencia invisible en la pareja. Revista La Cibeles, no 2, 1-6.

Braverman, H. (1974) Trabajo y fuerza de trabajo. En Toharia, L. (comp.) (1983) El mercado de trabajo: Teorias y aplicaciones. Madrid, Alianza Universal, 129-139.

Bruscas, I. (2009) El empresariado femenino en Aragón. Zaragoza, Instituto Aragonés de la Mujer.

Camarero, L.A. (2008) Invisibles y móviles: trayectorias de ocupación de las mujeres rurales en España. Ager, nำ 7, 7-31.

Del Valle, T. (2002) Modelos Emergentes en los sistemas y las relaciones de género. Madrid, Narcea.

Durán M.A (2009) El tiempo expropiado. Ponencia del Seminario Voces y Espacios femeninos, Universidad de Zaragoza, 28 de enero 2009.

Formichella, M.M. (2004) El concepto de emprendimiento y su relación con la educación, el empleo y el desarrollo local. Monografía realizada en el marco de la Beca de Iniciación del INTA (Ministerio de Asuntos Agrarios y Producción): Gestión del emprendimiento y la innovación, Buenos Aires, Instituto Nacional de Tecnología Agropecuaria.

http://biblioteca.municipios.unq.edu.ar/modules/mislibros/archivos/MonografiaVersionFinal.pdf

Frutos, L.Mํa .; Castelló, A. y Hernández Navarro, Mํㅗ.L. (2009) El déficit de población femenina y su importancia en los problemas demográficos estructurales de los espacios rurales: El caso de Aragón. En López Trigal, L.; Abellán García, A.; Gordeau, D. (coord.) Envejecimiento, despoblación y territorio. Universidad de León, 163-174.

Gamonal, S. (2003) El principio de la no discriminación por razones de sexo. Cuadernos Jurídicos, $\mathrm{n}^{\mathrm{o}}$ 18, 83-105.

García Ramón, MạD. (1989) Para no excluir del estudio a la mitad del género humano: un desafío pendiente en Geografía. Boletín de la Asociación de Geógrafos Españoles, no 9, 27-48.

García Ramón, Mํ.D. y Nogué, J. (1999) Un análisis desde la perspectiva de género. Journal of geography in Higuer educatión, no13, 1. pp. 110-112. Citado por García Ramón, M.D. (1989): Para no excluir del estudio a la mitad del género humano: un desafío pendiente en Geografía. Boletín Asociación de Geógrafos Españoles, nํㅜ 9, 27-48.

García Ramón, Mํㅗ D. (2005) Respondiendo a un desafío pendiente en geografía. El enfoque de género visto desde España. Geographicalia, nº 48, pp. 55-76.

Gupta, V. \& Bhawe, N. (2007) The Influence of Proactive Personality and Stereotype Threat on Women's Entrepreneurial Intentions. Journal of Leadership \& Organizational Studies, vol. 13, no $\frac{4}{4}, 73-85$.

Kwong, C.; Jones-Evans, D.\& Thompson, P. (2012) Differences in perceptions of access tofinance between potential male and female entrepreneurs. Evidence from the UK. International Journal of Entrepreneurial BehaviourG Research, vol. 18, nำ 1, 75-97. 
Manolova, T.S., Brush, C.G., Edelman, L.F. \& Shaver, K.G. (2012) One size does not fit all:Entrepreneurial expectancies and growth intentions of US women and men nascent entrepreneurs. Entrepreneurship \& Regional Development, vol. 24, nํㅜ 1-2, 7-27.

Marlow, S. \& McAdam, M. (2013) Advancing debate: An epistemological critique of the relationship between gender, entrepreneurship and firm performance. International Journal of Entrepreneurial BehaviourE Research, vol. 19, ํㅡำ 1 .

Maya, A. y Hidalgo, G. (2005) Situación laboral de la mujer en Castilla y León. Geographicalia, no $49,111-137$.

Mies, M. (1998) ¿̇Investigación sobre las mujeres o investigación feminista? El debate en torno a la ciencia y la metodología feministas. En Barta, E. (comp) (1998) Debates en torno a una metodología feminista. México, PUEG-UAM, 63-102.

Nieto, C. (2004) Las empresarias rurales malagueñas. La respuesta de las mujeres al mercado laboral. Málaga, Publicaciones de la universidad de Málaga.

Ortiz, A.Ma (2007) La situación del empresariado femenino. Departamento de administración de empresas y comercialización e investigación de mercados (marketing). Universidad de Sevilla. http://prometeo.us.es/idea/publicaciones/libroequal.pdf (Consulta: 04.12.2012).

Perez Quintana, A.; Hormiga, E. (2013) Los estereotipos de género y la intención de emprender". IV Jornadas economía feminista, Universidad de Pablo de Olavide de Sevilla.

http://riemann.upo.es/personal-wp/congreso-economia-feminista/files/2013/10/Perez-AnaHormiga-Esther.pdf (Consulta:15/03/2014).

Ribas, M. y Sajardo, A. (2005) La diferente participación laboral de las mujeres entre las cooperativas y las sociedades laborales. Revista de Economía Pública, Social y Cooperativa, ํㅡㄴ 52, 267-278.

Rico González, M. (2003) La mujer dentro del proceso migratorio y de envejecimiento en el medio rural de Castilla y León. Ayuntamiento de Valladolid.

Rico González, M. (2005) "El turismo como nueva fuente de ingresos para el medio rural de Castilla y León". Cuadernos de Turismo, núm. 16, 175-195.

Rico González, M. y Gómez García, J.M. (2005) La situación laboral de las mujeres en el medio rural de Castilla y León. Revista Universitaria de Ciencias del Trabajo, nª . 4, 299-322.

Robb, A.M. y Watson, J. (2008) Comparing the performance of female-and male- controlled SMES: Evidence from the United States and Australia. Frontiers of Entrepreneurship.

Romero, M. (1990) La actividad empresarial femenina en España. Madrid, Instituto de la Mujer.

Romero, M. (1994) El empresariado femenino en España: Riesgo económico e identidad femenina. Tesis doctoral (en línea), Universidad Complutense de Madrid.

http://eprints.ucm.es/tesis/19911996/S/1/S1006401.pdf (Consulta: 10.11.2011).

Romero, M. (2005) Mujer y empresa. Por una estrategia de ajuste recíproco. Perspectivas y Planteamientos. Lan Harremanak: Revista de relaciones laborales, $\mathrm{n}^{\circ}$ 13, 133-152.

Souza, E. (1986) División sexual del trabajo: el trabajo también tiene sexo. Mujery trabajo en América Latina. Montevideo, Ediciones de la Banda Oriental. 
Swain, M, B. (2005) "Las dimensiones de género en la investigación sobre turismo". Revista Política y Sociedad, Vol. 42, no 1, 25-37.

Swain, M. (1995) Gender in Tourism. Annals of Tourism Research, 22 (2), 247-267.

Verheul, I., Uhlaner, L. y Thurik, R. (2005) Business accomplishments, gender and entrepreneurial self-image. Journal of Business Venturing, vol. 20, no 4, 483-518.

Watson, J. \& Robinson, S.(2003) Adjusting for risk in comparing the performances of maleand female-controlled SMEs. Journal of Business Venturing, vol. 18, nำ 6, 773-788.

Williams, J.E. \& Best, D.L. (1982) Measuring Sex Stereotypes. Sage Publications Inc., Beverly Hills, CA.

Wood, W. y Eagly, A.H. (2002) A cross-cultural analysis of the behavior of women and men: Implications for the origins of sex differences. Psychological Bulletin, vol. 128, 699-727. 
